United Kingdom and the British Colonies are the best customers of the Swedish match trade.

EXPORTS TO THE UNITED STATES.

The values of the exports of chemical products to the United States in four years, I907-I9IO, were as follows:

\begin{tabular}{|c|c|c|c|c|}
\hline Articles. & 1907. & 1908. & 1909. & 1910. \\
\hline $\begin{array}{l}\text { Cement................... } \\
\text { Chemicals (chiefly caustic }\end{array}$ & $\$ 41,000$ & $\$ 7,000$ & $\ldots \ldots$ & $\cdots \cdots$ \\
\hline alkalies). ............ & 6,000 & 4,000 & 7,000 & $\$ 13,000$ \\
\hline Fusel and tar oil. . . . . . . & $\ldots$ & 2,500 & $\ldots \ldots$ & 5,400 \\
\hline Glue,$\ldots \ldots \ldots \ldots \ldots \ldots$ & $\ldots$ & 3,000 & $\ldots \ldots$ & $\cdots \ldots$ \\
\hline Matches.$\ldots \ldots \ldots \ldots \ldots$. & 112,000 & 124,000 & 207,000 & 157,000 \\
\hline $\begin{array}{l}\text { Paper................ } \\
\text { Wood pulp: }\end{array}$ & 276,000 & 496,000 & 850,000 & 623,000 \\
\hline $\begin{array}{r}\text { Chemical........... } \\
\text { Mechanical........... }\end{array}$ & 499,000 & $1,060,000$ & $\begin{array}{c}1,318,000 \\
\ldots \ldots\end{array}$ & $\begin{array}{r}1,636,000 \\
4,500\end{array}$ \\
\hline
\end{tabular}

The United States purchases Swedish bar iron to the amount of over $\$ 1,000,000$ annually, and about $\$ 600,000$ worth of wire rod, as well as smaller quantities of several other forms of the metal. The export of Swedish ferrosilicon to the United States was valued at $\$ 5,000$ in 1909 , while in rgro it had attained a value of $\$ 5 \mathrm{I}, 000$. Of much greater interest is the sudden increase of the American demand for Swedish iron ore. The value of the importations ranged from $\$ 12,000$ to $\$ 32,000$ during the period I907-rgog. In igro the figure reached $\$ 98_{3}, 000$. For a number of years past America has purchased Swedish pig iron to an average annual value of $\$ 90,000$.

IMPORTANCE OF THE SWEDISH MARKET FOR CHEMICAL GOODS.

As the American manufacturers of heavy and finer chemicals approach the point of competing with Germany and Great Britain in the world's markets, they will find in the Swedish trade an important field. For the time being there is an opportunity to extend trade in colors, paints and pigments, blacking, varnishes, and a few similar articles, the value of which is already appreciated in Sweden. The consumption of quinine preparations is also relatively large.

The outcome of the Swedish studies in the electric smelting of iron ores may mean much for certain iron deposits in the United States where conditions are not unlike those existing in Sweden.

\section{FUEL ECONOMY IN FACTORIES. ${ }^{1}$}

By C. E. Lucke.

Received November 13, 1911.

Maximum economy in the use of fuel as one of the primary raw materials in manufacturing is to be measured by the least consumption per unit of manufactured product, a statement ridiculously easy to make but most difficult of realization. The difficulties in realization arise from the almost infinite variety of combinations in the uses to which the heat liberated by combustion may be put, and the relation of heat quantities entering into each of the different uses

1 Address delivered at the joint meeting of the A. C. S., S. C. I and A. E. S., New York, November 10, 1911. of the heat, the difficulty in measurement of heat quantities, and the bulkiness of the records of the heat balance required to keep track of the heat disposition in the establishment. No one would think for a moment, in conducting the financial operations of a business, of dispensing with records of expenditures and income or fail to provide a more or less elaborate cost system for distributing the expense over the various parts of the apparatus used in production and for dividing cost of the products into the different elements that make it up. No one would think of attempting to economically manufacture a steam engine without providing for a regular systematic determination of the cost of the crank-shaft and in some instances for the distribution of the cost into elements of raw steel from which it was made, the operations of forging, machining, transporting and handling, and for the fixing of the overhead charges, all of which are determinable items, and to which may be added many others of lesser importance, carrying the process as far as the information is worth. Cost information is worth as much as the possible saving in cost of production to which the information leads, so that manufacturing managers must use and do use their best judgment in deciding how far they will detail their cost records, but it will be difficult to find one who would attempt to carry on his business without cost records as elaborate as the conditions warranted. It is quite the same with fuel economy, that is, so far as need of records is concerned but by no means the same in practice. There can be no rational attempt made toward fuel economy in a given system of manufacture using fuel without a knowledge of the distribution of the heat of that fuel throughout the establishment, and it is no more difficult to trace the heat throughout a system supplied with heat than it is to trace expenses for material and labor in a crank-shaft or fly-wheel relating each to the total expense incurred. though it is quite possible that the information may not be worth enough to warrant as complete a distribution of the expense of heat supply or as elaborate a system of records as would be warranted in the case of labor or materials entering directly into the factory product. However, there can be no question as to the absolute necessity for some heat accounting to determine the coal heat charge to be attached to each individual process using heat and to show sources and quantities of utilizable waste heat, however simple the system of the accounting may be, nor can there be any doubt as to the increasing justification for more and more elaborate records as coal cost forms an increasing fraction of the total cost of production. How many factories there are in which no more records of heat are kept than the cost of coal per month is impossible to state in the absence of statistics, but according to my own observations the number will be very large, probably in excess of three-quarters of the total establishments. It is not surprising, therefore, that maximum heat economy is so seldom attained or that managers are so constantly besieged and bewildered by, and so much dependent upon, the statement of promoters of all sorts of schemes 
who promise to accomplish most impossible economies and yet whose absurd arguments cannot be answered because of absence of data. How many managers, having under their direction steam plants for power, know the cost of their draft sufficiently closely to be in a position to judge the value of a new draft system offered for their consideration? How many know even the cost of the power itself so as to be in a position to judge a new power system offered as a substitute? It is safe to say that those who have data of the above sort constantly up to date are far less in number than those who know the total cost of their product and its fractional part of overhead charges, labor and materials and yet every one will claim a desire for fuel economy.

Heat accounting is necessary. How much accounting depends upon the fraction of total production cost chargeable to fuel in one form or another and through these accounts economy may be affected most readily by attacking first the big losses or items of large heat waste. In this way and only in this way may the best results be obtained from a given. installed system in operation or the relative value of a competing system judged, as a preliminary to a change of system. In many cases it will be found that managers believe they have records of their heat distribution and power cost but these figures are what their so-called operating engineer hands them. It is most curious how the engine room cost figures are so seldom subjected to critical analysis and checking to make sure that they include all the items that are properly chargeable to that account or to insure the correctness of the items that are reported. This is in striking contrast to the care with which so-called factory cost systems will be installed and operated by experts in the same establishment which is satisfied with the accounting of a skilled mechanic called an engineer for its power and heat cost.

Economy is then always a question of accounting, that is, correct accounting as elaborate as the conditions may warrant in every establishment. The attainment of maximum economy is, however, also largely a question of the operating system used. It is one thing to know for a given plant in operation where the heat losses are and how much they are; it is another thing to know how to reduce these losses in the existing system by modifying the detail of management or even altering connections or substituting new units, but it is quite a different thing to know when or how to change the system as a whole to an entirely different one or how to compare broadly existing with possible new systems.

In a general discussion of fuel economy, it seems as if the question of system ought to be put in the first place, especially if it can be shown that there is any fundamental and essential differences in the losses involved and hence in the net fuel economy of the system applied to a factory. It may be assumed that in a factory fuel enters directly or indirectly into four classes of services, all of which are essential to the making of the product:

r. Power.
2. Factory heating in cold weather.

3. Factory lighting.

4. Direct manufacturing processes, such as heating, cooling, evaporating, condensing, melting and drying.

In a given establishment the system involving all these processes may be self-contained or may be externally sustained. A system is self-contained when all four classes of service may be derived from the same coal supply. It is not self-contained when it is partly or wholly dependent upon external supplies as, for example, gas for lighting alone, electricity for lighting alone, or for power in addition, and perhaps for high temperature furnace work with coal for the other services. In all systems where coal is used in manufacturing, its heat is rarely applied directly to the service to which it is ultimately put, but its heat is usually transferred in part to steam or transformed in part to combustible gases, giving in the former case the steam system of heat distribution and in the second case the gas system. Where heat of coal is directly applied to such service as high temperature heat supply, that service can always be better done by gas derived from the coal in just about the same degree of gain in efficiency as in the gas over the coal-fired cook stove. There is one exception to this, however, and that is where fixed carbon enters as a necessary element in a thermal reaction, but these cases are so clearly exceptional as to need no comment.

The primary process in the use of heat is, therefore, the making of steam on the one hand, or the gasifying of coal on the other, and the direct loss encountered in either of these processes is the first factor for measurement and record in the heat-accounting system. This first step of conversion may be made to take place with an average efficiency of 65 per cent. to 75 per cent. for the steam system, depending on the coal, the goodness of the firing and the type of equipment, and an efficiency from 75 per cent. to $8_{5}$ per cent. for the gas system, showing a clear gain of about ro per cent. for the gas system on the average for this first step, with, however, a limitation and this limitation is the inability of the producer to handle as wide a range of fuel with equal success to that attainable in the boiler.

Steam once made is transmitted in pipes for short distances only and under high pressure with constant heat loss for every foot and involving high maintenance charges, on its way to engines for shaft power or electrical generation. The gas, however, may be transmitted at low pressure over very long distances to all the buildings of large establishments or to neighboring establishments several miles away or from a central gas generating station dozens of miles distant through pipes cheaper than those required for steam and with almost no maintenance cost in comparison. This pipe distribution cost is the next item in the accounting and without setting down numerical values is again plainly in favor of the gas system, which involves no heat loss whatsoever while the steam involves a large one and in which the pipe maintenance costs are hardly comparable at all. 
The next step is the conversion into work, in the engine, of the heat carried by either the gas or the steam, and here the balance is again in favor of gas as the gas engine is a much more efficient heat converter than the steam engine in the small sizes found in the average factory and even in larger sizes also, though there to a lesser degree. Few factories would find any occasion to use engine units exceeding 1000 h. p., which size, operated condensing, whether of the turbine or compound Corliss sort, will yield thermal efficiencies less than 20 per cent., whereas, operated non-condensing, these efficiencies would drop to at least I5 per cent. A smaller steam engine of, say, I00 h. p., will be less efficient and the turbine would not be so good as the piston type, though the difference would not be so very great. For this size the efficiency that could be counted on would be about I 5 per cent. operated condensing and not over Io per cent. operated non-condensing. Compare these efficiencies with the sure and substantially constant thermal efficiency for the gas engine in all sizes, of 25 per cent., which indicates a margin in favor of the gas of at least 5 per cent. for large steam engines condensing, Io per cent. for the smaller condensing and also for the large non-condensing and $\mathrm{I} 5$ per cent. for the small non-condensing steam engines. These efficiencies are not the best ever obtained but are about as good as one can count on obtaining in factory work. Of course, load fluctuations will affect the result but these figures are for a load equally favorable to the two classes of machines.

If electricity is generated and transmitted for lighting or for use in electric motors the efficiency of electrical generation, transmission and reconversion to power and light is the same for both systems. It is right here, however, that another item may be put on the credit side of the account in favor of gas and one that is not generally or sufficiently appreciated, arising from the possibility of eliminating some of the electrical equipment, if not all. If machines are to be driven in various distant parts of the establishment there is no reason why we should not do as has been done more often in Germany, and that is to set down small individual gas engines at the spot where power is required and transmit gas with practically no loss instead of generating electricity and transmitting it to electric motors with three losses. This would not only save the expense of the electrical equipment but would save all electrical losses, which are often considerable, especially when generator and motor work at unfavorable loads. This is a perfectly feasible proposition and will give substantially the same efficiency of conversion as is obtainable in a single large central engine, a fact that distinguishes the gas system more than anything else from the steam system. Concentration of many small steam engines into a single large one always results in steam economy, a fact which has led to constant concentration of steam systems into larger and larger central generating units, so that the steam may be regarded as a centralizing influence whereas, on the contrary, the constancy of gas engine efficiencies in large or small sizes must characterize the gas system as a decentralizing influence in the interests of economy.

Take next the question of factory lighting of the self-contained system, which may be electrical with current supplied by either steam- or gas-driven generators and which can be only electrical for steam enginedriven generators but which may be something else when gas is available. There is no good reason for assuming that mantle lights of fair brilliance and moderate gas consumption cannot be produced to operate on weak producer gas for factory lighting and as soon as they become available, as they surely will when the demand becomes pressing enough, mantle gas lighting with producer gas will displace to a very large extent electric lighting in those establishments where the gas system is used for power and heat and gas transmission substituted, at least in part for electric. This sort of change while not feasible now, because of the lack of development of weak gas, mantle lights, will add another credit item in favor of the complete gas system and the possible gain in fuel economy for lighting should be incentive enough to produce these lights and warrant their quite general use.

Heating of buildings is almost universally accomplished by means of steam- or water-heated radiating surfaces at a temperature of 200 degrees Fahrenheit or thereabouts and there is no good reason for changing the system. The preparation of this low-pressure steam or moderately hot water can be done with equal efficiency by either the gas or steam system in cold weather, though the latter again receives a credit charge for all the rest of the year when heat is not required. For example, if the exhaust steam from steam engines is used it must be at approximately atmospheric pressure to give a high enough temperature, or live steam must be used either alone or added through reducing valves as make-up. In any case the heat put into the heating system gives about Ioo per cent. effect in the warming of buildings, especially when drips are returned. This is also the case for the gas system as jacket water heat and exhaust gas heat can be combined for the same purpose and fresh gas drawn upon through thermostatic gas burners to supply any deficiency. By either method the effect is the same, full use of waste heat and roo per cent. efficiency in the use of fresh supplies of heat in the warming of the building. During the time of no building heat requirement, which in this locality lasts for more than half the year, the waste heat of the steam engine is far in excess of that of the gas engine, especially if the former be non-condensing as is usually the case where exhaust steam-heating systems are in use so that measured over the whole year the gas system is again most favored.

There remains now to examine the: possibilities of credit or debit items for the two systems in applying the heat to the direct manufacturing processes, which may be for convenience divided into low temperature heating and high-temperature heating, the former including most of the evaporating and drying 
processes and the latter rosting, baking, melting. etc. All low-temperature processes can be carried on by steam-jacketed chambers or steam coil apparatus. using live or exhaust steam, a fact that has led to the design and mechanical perfection of many appliances not regarded as standard and for which there is no gastheated equivalent. There is no good reason. however, why equivalent apparatus should not be quite as effectively designed and with efficiencies over go per cent. for operation with gas burners but like the mantle light the need has not yet been strong: enough to warrant their production. Such evaporators concentrators, cookers and uriers as fall in this class will, when gas-heated offer still further simplification of piping and reduction of piling loss oter their steam-heated equivalents and should be equally effective. High-temperature heating can be accomplished only by oil, piped illuminating gas or independent coal fires with the steam factory system while the gas system offers a possibility of producer gas-fired furnaces for practically all services and with almost perfect temperature control better by far than is possible with oil or coal and more economical because excess air and incomplete combustion can both be eliminated.

Thus, for the heating processes of manufacture, the gas system offers the same high-temperature source of heat, a gas fire, for all, while the steam system requires fresh fuel for the high temperatures, accomplishing the low-temperature service with live or exhaust steam. but the former is not an accomplished fact simpiy because no one is ret prepared to sell gas-fired appliances to take the place of steam-heated ones.

Comparing gas and steam systems broadly by summarizing the preceding brief analysis, it appears that the self-contained factory plant may be much more economically operated by the former than by the latter for all the services of power, lighting, building and process heating, but this is not all, for there is also in favor of the gas a very great simplicity in the heat balance determination for the gas over the steam so very great as to make it easier to keep up the operating economy nearer to the high possibility by quick and easy determination of wastes. For example, by means of a central gas meter and as many individual distributing meters as the separate consumptions of gas, the gas generated may be easily known as well as its distribution throughout the plant for all purposes by no more complicated procedure than the reading of meter dials which any good boy can do. Add to this recording calorimeters, and gas meter readings can be reduced by one multiplication to heat consumed by each part of the system. With such a ready check on consumptions and losses, it is sure that heat-accounting will be practiced because the cost of the account will be so small and, therefore, the plant may be and will be operated at somewhere near its good economy point. This is in most striking contrast to the case of the steam system where the possible economy is not only less but where in addition the realized economy is so much below its own maximum possibility simply because of the difficulty of making the measurements necessary to a heat balance with reasonable accounting costs. In the first place it is impossible to continuously measure the heat supplied in steam generated because there is no reliable and cheap steam meter arailable and even if there were, the heat equivalent of a pound of steam constantly varies with feed temperature, steam pressure and its wetness or superheat. Pipe line losses can be determined only by collecting and weighing drips; steam consumptions of other appliances and their heat equivalents is a question of many recording steam meters, steam calorimeters, thermometers, pressure gauges and automatic water weighers. To keep up all the instruments of this sort that would be needed so that they will remain reasonably accurate and to make the calculations of combining the various readings to get a heat balance would in most cases cost more than the information would be worth though a partial record is always a paying thing when designed to include the big items.

Why is it then, in view of both the higher possible economies of the seli-contained gas factory system for the four classes of factory service and the correspondingly easier and cheaper fuel-accounting that would follow its use, that there is to be found no such system in use? The answer is as complex as a detailed study of the systems, but a few facts stand out more prominently than others: First, there must be put the inertia of the human mind, which resists the mental effort necessary to bring about a change when things seem to be running fairly well in the older way. There is always a latent suspicion that the new thing may not work however clear a case is made out for it on paper, and even if the manager himself is convinced in the light of his trained ability for clear independent thought, he may not be able to convince his board of directors who are ordinarily incapable of thinking in terms of anything but past performances of the factory, however willing they may be to deal in the futures of stocks and bonds. So far there has been in this particular case some good reason for suspicion, not of the scientific engineering possibilities but of the business expediency of a general change because of the lack of standardization or mechanical perfection of some of the needed appliances. We have no producer gas mantles for lighting, no gas-fired evaporators, concentrators or driers, and most important of all, we have no universal gas producer capable of economically using any available solid fuel, but it is for us to make these things, and my main object in speaking on this subject is to stimulate their production by showing a motive. Let the gas appliance makers get to work on the problem of adapting apparatus for all the manifold services of lighting and heating to the use of weak producer gas and let us all, chemists and engineers, try to solve the gas producer problem. Progress in the perfection of appliances for using producer gas will stimulate the demand for the right sort of gas producer to generate it, and the appearance of the producer on the market will force 
the creation of gas-burning industrial apparatus so that each reacts on the other. As soon as the industrial world concerned with fuel economy in manufacturing demands these things in a sufficiently. strong and positive manner they will be produced.

\section{DEFLOCCULATION. ${ }^{1}$}

. By Edward G. Acheson.

Received November 18, 1911.

It is with much diffidence that I come before you to speak on a subject that has not yet emerged from the embryonic state. My latest experimental researches had to do with it; I believe it will rapidly grow in importance in the scientific industrial world; and finally much work of a strictly scientific character remains to be done to reduce the fragmentary knowledge we now have of it to an exact science.

In my labors devoted to working out and developing industrial and commercial projects, I have upon several occasions found reactions, conditions and results that did not harmonize with the accepted theories and formulae of scientific men. Being an earnest believer in publicity, in order that any possible benefits that might accrue to the common welfare may the more quickly be enjoyed, I shall lay before you a detailed account of my experiments on the deflocculation of inorganic bodies. It will become very evident, as my story unfolds, that throughout the series of experiments described and the working hypothesis employed, I was wholly disregarding the prevailing theories, and that I unconsciously entered the field of colloids.

Having worked out the problems involved in the manufacture of graphite from coal and other carbonaceous materials, I undertook, in the summer of $\mathrm{I} g \circ \mathrm{I}$, the introduction of this artificially made graphite into the crucible trade. My first efforts were devoted to the making of a satisfactory crucible of my graphite, using as a binding material American clays. Many failures were met with, and I found it difficult to locate the cause of the failure, whether with the graphite or with the clay. I soon learned that the Inanufacturers of crucibles in the United States invariably used, as a binding agent for the graphite in the crucible body, clays imported from Europe. I secured samples of these imported clays, and found them much superior to the American ones in plasticity and tensile strength.

Chemical analysis failed to disclose the cause of the physical differences existing in the clays. The question involved interested me greatly, and I decided to endeavor to determine what produced the variations. I found it generally stated in the books that residual clays were non-plastic, and sedimentary clays were more or less plastic. Here was the starting point. Plasticity was developed by or during the act of transportation from the point of formation to the final resting place of the clay. I did not believe there was anything in the simple act of the suspension

${ }^{1}$ Address delivered before the Society of Chemical Industry, London, November 7,1911 . in water that would produce the effect noted, and therefore looked for the cause of the foreign matter carried by the water. It seemed that the most likely agents were the organic substances washed from the forests into the running waters. With this idea in view, I made a few experiments with those substances I thought likely to be found in the washings of vegetation. One of my early experiments was to treat kaolin with a solution of tannin, and $I$ at once noticed less water was needed to produce a given degree of fluidity; also that the tensile strength and plasticity were increased.

"Tests were made on the increased tensile strength of clay, as the result of treatment with organic matter, and it was found that briquettes made of Harris kaolin and dried at $120^{\circ} \mathrm{C}$. would break with a load of 5.73 kilograms per square centimeter, while the same clay, after treatment with 2 per cent. of catechu for a period of ten days, then formed into briquettes and dried at $120^{\circ} \mathrm{C}$., would not break until the load was increased to 19.75 kilograms per square centimeter-an increase of more than 244 per cent.

I now began to wonder whether or not the effect I had discovered was known, as it might have much value to an industry of such colossal dimensions and antiquity as clay-working. Moreover, it would be amazing if it should not be known, in view of the tremendous amount of experimental work that had been done on that art. I searched for some record of the addition of organic matter to clay during its working, and only one instance could I find, that of the Egyptians in brick-making, as recorded in the fifth chapter of Exodus. The accepted theory of using straw fiber as a mechanical binding agent had never appealed to me. Straw, however, contains no tannin, and the effect I had found had always been produced with tannin, or a substance containirig tannin. I procured some straw, boiled it with water, decanted the resultant reddish brown liquid, and mixed it with clay. The result was like that produced with tannin, and equal to the best I had obtained. It now seemed likely that the Egyptians were familiar with the effect I had discovered, and believing this was why they used straw in making brick and were successful in substituting stubble for the straw, I called clay so treated "Egyptianized Clay."

The effect of organic matter, as typified by tannin, in producing deflocculation and a resultant colloidal state of clay is very readily shown; for instance, I have here some powdered kaolin, a small quantity of which I will place in a test tube, add water, and after shaking, set aside. Another portion of the kaolin I will put into a beaker, and moisten with a water solution of tannin, to which a small amount of ammonia has been added. After a thorough mixture has been made, using a glass rod to stir with, to eliminate as much as possible any grinding action, I will add more water and divide the contents of the beaker between two test tubes. To one of the tubes containing tannintreated clay I will add a little common table salt. The three tubes I will place here before you, that we may examine them later. 